\title{
Phenytoin impairs the bioavailability of dexamethasone in neurological and neurosurgical patients
}

\author{
JB CHALK, K RIDGEWAY, TRO'R BROPHY, JDN YELLAND, MJ EADIE \\ From the University Departments of Medicine and Surgery, and Neurosurgical Unit, Royal Brisbane Hospital, \\ Brisbane, Australia.
}

SUMMARY Plasma concentration-time data after oral and intravenous administration of dexamethasone have been subjected to pharmacokinetic analysis in six neurological or neurosurgical patients taking the steroid with phenytoin, and in nine patients (one studied twice) taking dexamethasone without phenytoin. An additional patient was studied before and during phenytoin intake. Apparent volume of distribution was similar in the two groups, but the group treated with phenytoin had an almost statistically significantly shorter dexamethasone mean terminal half-life, an approximately trebled mean plasma clearance, and a mean oral bioavailability of the steroid of only $33 \%$, compared with a mean $84 \%$ oral bioavailability in those not receiving phenytoin. To achieve a given plasma dexamethasone concentration, patients treated with the steroid and phenytoin may need oral dexamethasone doses several times those required by patients not receiving phenytoin.

The anticonvulsant phenytoin is now being used successfully to reduce the incidence of epilepsy after craniotomy.' At and around the time of such surgery the glucocorticoid dexamethasone is often given to help control intracranial pressure. There is evidence from experimental studies, carried out with radioactive steroid, that phenytoin intake increases the clearance of dexamethasone and shortens its plasma half-life. ${ }^{23}$ This interaction between the drugs might be expected to occur when phenytoin and dexamethasone are used together, as occurs at times in neurological and neurosurgical practice. In a previous study in six neurological patients ${ }^{4}$ we found that dexamethasone was incompletely bioavailable when given by mouth. To an extent the lowest bioavailabilities correlated with simultaneous intake of phenytoin, but the numbers studied were too small for definite conclusions. We have now extended these observations and have obtained evidence that phenytoin intake is associated with a substantial reduction in the oral bioavailability of dexamethasone, a finding which has implications for the Address for reprint requests: Prof Mervyn Eadie, Dept of Medicine, Clinical Sciences Building, Royal Brisbane Hospital, Brisbane 4029, Australia

Received 4 January 1984 and in revised form 29 March 1984. Accepted 1 April 1984 dose of the steroid necessary to treat neurological and neurosurgical patients.

\begin{abstract}
Materials and methods
Patients studied

The subjects studied comprised 16 patients who gave informed consent, and received dexamethasone therapy for various neurological or neurosurgical conditions. Nine of these patients did not receive phenytoin at any time; six did receive the anticonvulsant. One subject (Subject A) was studied twice, once before and once during phenytoin therapy. One of the nine subjects who did not receive phenytoin (Subject F) was also studied twice, five weeks apart. Thus the whole investigation comprised 18 studies in 16 subjects. The investigational protocol had received institutional ethics committee approval. Personal details of the patients, of the disorders for which they received dexamethasone, of their concurrent medication and the duration of their phenytoin therapy at the time of study, are provided in table 1 . Subjects $H, I, M, N, O$ and $P$ were included in a previous publication ${ }^{4}$ but their data have here been reworked by a different method of data analysis, as described below.
\end{abstract}

\section{Investigational design}

During the course of routine high dose oral dexamethasone therapy a single intravenous steroid dose of the same magnitude as the patient's oral dose $(4 \mathrm{mg}$ dexamethasone base in all subjects except $C$, who received 
Table 1 Personal details of the two groups of subjects

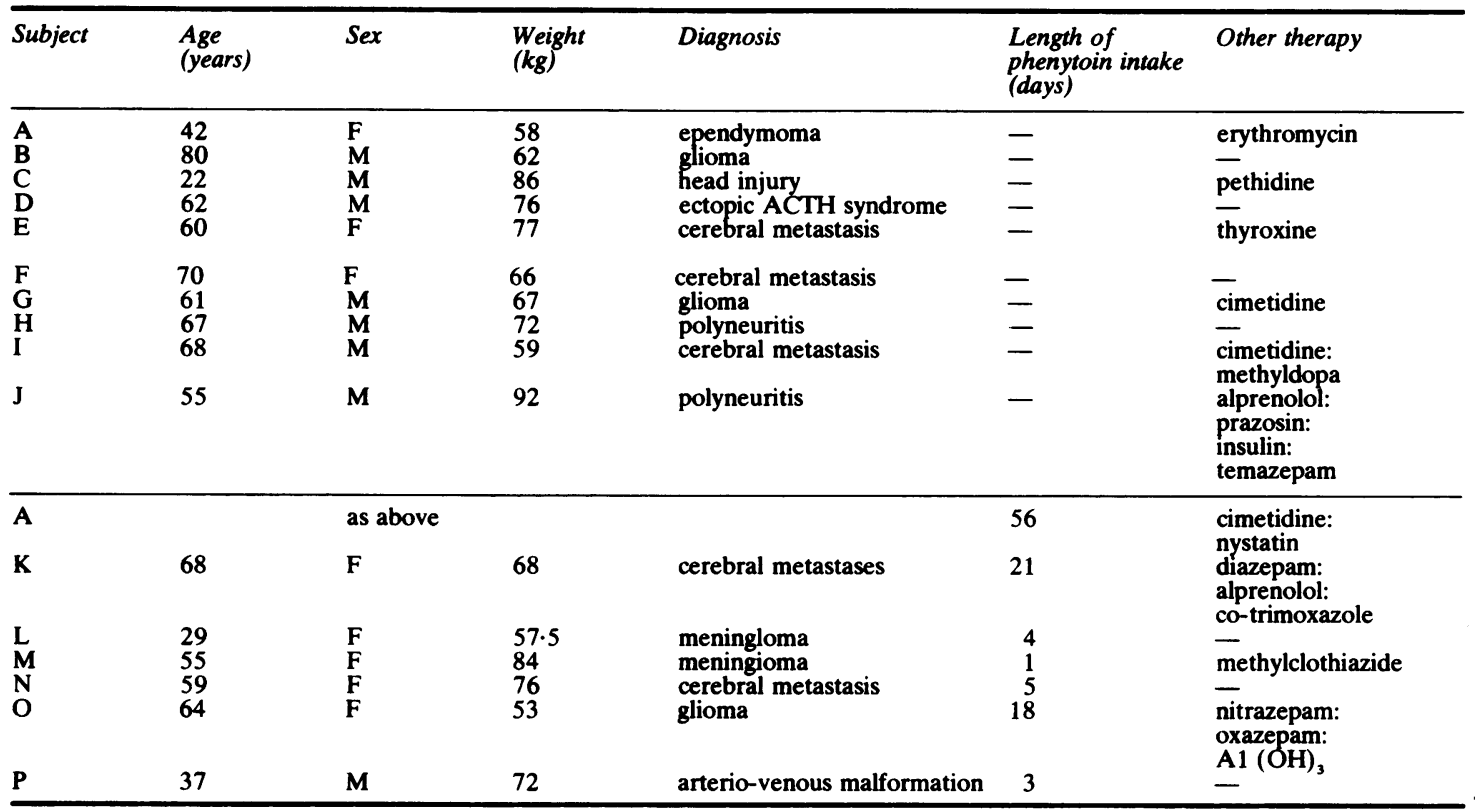

$20 \mathrm{mg}$ ) was given to replace the morning oral steroid dose, and plasma dexamethasone levels were followed at intervals for the next 8 hours. Whenever practicable, the steroid dose immediately prior to the study was given at least 8 hours earlier; if the patient was receiving dexamethasone 6 hourly the dose following the test dose was deferred for 2 hours to permit an 8 hour study. Whenever feasible, within 24 hours of the intravenous dose the study was repeated with the same dexamethasone dose, given orally. Routine patient care and all other therapy continued unaltered during each study.

Forearm venous blood was collected for dexamethasone assay as near as possible to the following times in relation to drug administration: $0,0 \cdot 16,0 \cdot 33,0 \cdot 5,0 \cdot 75,1 \cdot 0,1 \cdot 5$, $2 \cdot 0,3 \cdot 0,4 \cdot 0,5 \cdot 0,6 \cdot 0$ and $8 \cdot 0$ hours.

\section{Dexamethasone assay}

Plasma dexamethasone concentrations were measured by a minor modification of the high performance liquid chromatographic assay of Cham et al. ${ }^{5}$ The assay modification permitted simultaneous measurement of endogenous plasma cortisol concentrations.

\section{Data Analysis}

A two compartment open linear pharmacokinetic model ${ }^{\circ}$ provided a satisfactory fit to the data in all instances. The intravenous and oral plasma level-time data for each subject were fitted simultaneously to linear equations of the forms

$$
\begin{aligned}
& C=a e^{-\alpha t}+b e^{-\beta t} \text {, and } \\
& C=a e^{-\alpha t}+b e^{-\beta t}-c e^{-\gamma t} \\
& \text { (where } \gamma=k_{a b s} \text {, the absorption rate constant), }
\end{aligned}
$$

for the intravenous and the oral data respectively, using a
Pascal language iterative curve fitting program based on Marquardt's (1963) algorithm. ${ }^{\text {? }}$

The program used is part of the Stemkinetics software written for Apple II microcomputers by Stemsoft Pty, Ltd. Because of the larger number of data points available in paired studies carried out only 24 hours apart, the simultaneous fitting gave greater precision to the estimates of disposition parameters than separate curve fitting to each set of intravenous or oral data.

Area under the plasma level-time curve over the period of measurement $\left(\mathrm{AUC}_{0 \rightarrow \mathrm{t}}\right.$ ) was calculated using trapezoidal rule integration, with $\mathrm{C}_{\mathrm{o}}$ in the case of intravenous data being obtained from the sum of $a$ and $b$. Area under the curve to infinity $\left(A \cup C_{0 \rightarrow o o}\right.$ ) was calculated by adding to the AUC $_{0 \rightarrow t}$ calculated as above the quantity $\mathrm{Ct} / \boldsymbol{\beta}(=$ AUC $\left._{(\rightarrow o 0}\right)$. Where the experimentally measured $C_{0}$ had a positive value, as it did in 11 of the 36 studies, due to the presence of residual dexamethasone from the previous drug dose, $\mathrm{AUC}_{\mathrm{o} \rightarrow \mathrm{oo}}$ was corrected for this effect by subtracting the quantity $C_{0} / \beta$ from the value of $A U C_{0 \rightarrow \infty}$ derived as above.

Pharmacokinetic parameters were calculated in the usual way:

Clearance $(C L)=$ dose $/ A U_{0 \rightarrow 00}$

Apparent volume of distribution $\left(\mathrm{Vd}_{(\beta)}\right)=C L \beta$

Half-life $=\log _{n} 2 / \beta$ or $\log _{n} 2 / \gamma$

Bioavailability $(F)=\frac{\mathrm{AUC}_{\mathrm{o} \rightarrow \infty} \text { (oral) }}{\mathrm{AUC}_{\mathrm{O} \rightarrow \infty} \text { (iv) }} \times \frac{\text { dose (iv) }}{\text { dose (oral) }}$.

\section{Results}

Individual and group mean values for the phar- 
Table 2 Pharmacokinetic parameters in members of the two groups of subjects studied

\begin{tabular}{|c|c|c|c|c|c|c|c|c|c|}
\hline Subject & $\begin{array}{l}\text { Lag Time } \\
\text { (oral) } \\
\text { (hours) }\end{array}$ & $k_{\text {abs }}$ (hour-1) & $\begin{array}{l}\alpha \\
(\text { hour }\end{array}$ & $\begin{array}{l}\beta \\
\left(\text { hour }^{-1}\right)\end{array}$ & $\begin{array}{l}T 1 / 2(\beta) \\
\text { (hours) }\end{array}$ & $\begin{array}{l}C L \\
\left(L . k g^{-1} h r^{-1}\right)\end{array}$ & $\begin{array}{l}V d(\beta) \\
L . k g^{-1}\end{array}$ & $F$ & $r^{2}$ \\
\hline $\begin{array}{l}\text { A } \\
\text { B } \\
C^{*} \\
\text { D } \\
E \\
\text { F } \\
F^{*} \\
\text { G } \\
\text { H } \\
\text { I } \\
\text { J }\end{array}$ & $\begin{array}{l}0.13 \\
0 \\
0.61 \\
0.46 \\
0.34 \\
0 \\
0 \\
0.15 \\
0.33 \\
0.55 \\
0.08\end{array}$ & $\begin{array}{l}4.036 \\
0.659 \\
1.183 \\
2.676 \\
3.273 \\
1.268 \\
0.477 \\
3.627 \\
0.392 \\
0.827 \\
2.157\end{array}$ & $\begin{array}{r}2.362 \\
2.606 \\
1.902 \\
8.655 \\
1.867 \\
5.203 \\
2.720 \\
3.080 \\
13 \cdot 165 \\
1.141 \\
2.992\end{array}$ & $\begin{array}{l}0.244 \\
0.123 \\
0.057 \\
0.156 \\
0.195 \\
0.236 \\
0.295 \\
0.220 \\
0.392 \\
0.209 \\
0.290\end{array}$ & $\begin{array}{r}2.84 \\
5.66 \\
11.98 \\
4.46 \\
3.55 \\
2.94 \\
2.35 \\
3.15 \\
1.77 \\
3.32 \\
2.39\end{array}$ & $\begin{array}{l}0.502 \\
0.144 \\
0.080 \\
0.064 \\
0.207 \\
0.312 \\
0.262 \\
0.265 \\
0.285 \\
0.393 \\
0.272\end{array}$ & $\begin{array}{l}2.062 \\
1.176 \\
1.387 \\
0.414 \\
1.061 \\
1.325 \\
0.887 \\
1.203 \\
0.728 \\
1.886 \\
0.941\end{array}$ & $\begin{array}{l}1.36 \\
0.90 \\
1.07 \\
0.78 \\
0.82 \\
0.74 \\
0.60 \\
0.69 \\
0.77 \\
0.95 \\
0.55\end{array}$ & $\begin{array}{l}0.972 \\
0.866 \\
0.968 \\
0.986 \\
0.962 \\
0.984 \\
0.987 \\
0.985 \\
0.974 \\
0.993 \\
0.918\end{array}$ \\
\hline $\begin{array}{l}\text { Mean } \\
S D^{ \pm}\end{array}$ & & & & & $\begin{array}{l}3 \cdot 34 \\
\pm \\
1 \cdot 15\end{array}$ & $\begin{array}{l}0.272 \\
\pm \\
0.129\end{array}$ & $\begin{array}{l}1 \cdot 200 \\
\pm \\
0 \cdot 270\end{array}$ & $\begin{array}{l}0.84 \\
\pm \\
0.23\end{array}$ & \\
\hline $\begin{array}{l}\mathbf{A} \\
\mathbf{K} \\
\mathbf{L} \\
\mathbf{M} \\
\mathbf{N} \\
\mathrm{O} \\
\mathbf{P}\end{array}$ & $\begin{array}{l}0.44 \\
0 \\
0.94 \\
0 \\
3.66 \\
0.24 \\
1.94\end{array}$ & $\begin{array}{l}0.369 \\
2 \cdot 648 \\
8.640 \\
1.474 \\
0.134 \\
5 \cdot 769 \\
2 \cdot 196\end{array}$ & $\begin{array}{r}22 \cdot 558 \\
687 \cdot 894 \\
3 \cdot 046 \\
1 \cdot 563 \\
12.211 \\
39.017 \\
4.388\end{array}$ & $\begin{array}{l}1 \cdot 211 \\
1.822 \\
0 \cdot 196 \\
0 \cdot 140 \\
0.393 \\
1 \cdot 316 \\
0.937\end{array}$ & $\begin{array}{l}0.57 \\
0.38 \\
3.54 \\
4.98 \\
1.76 \\
0.53 \\
0.94\end{array}$ & $\begin{array}{l}1.001 \\
1.611 \\
0.520 \\
0.352 \\
0.287 \\
1.147 \\
0.670\end{array}$ & $\begin{array}{l}0.827 \\
0.884 \\
2.656 \\
2.527 \\
0.731 \\
0.872 \\
0.715\end{array}$ & $\begin{array}{l}0.21 \\
0.35 \\
0.15 \\
1.05 \\
0.19 \\
0.19 \\
0.14\end{array}$ & $\begin{array}{l}0.998 \\
0.947 \\
0.992 \\
0.937 \\
0.999 \\
0.983 \\
0.995\end{array}$ \\
\hline $\begin{array}{l}\text { Mean } \\
\stackrel{ \pm}{ \pm}\end{array}$ & & & & & $\begin{array}{l}1 \cdot 81 \\
\pm \\
1 \cdot 78\end{array}$ & $\begin{array}{l}0.798 \\
\pm \\
0.479\end{array}$ & $\begin{array}{l}1 \cdot 316 \\
\pm \\
0 \cdot 875\end{array}$ & $\begin{array}{c}0.33 \\
\pm \\
0.33\end{array}$ & \\
\hline
\end{tabular}

*excluded from tests of statistical significance

macokinetic parameters in the subjects are set out in table 2 together with coefficients of determination for the curve fittings. The time courses of plasma dexamethasone levels after intravenous and oral steroid dosage in Subject $\mathrm{A}$ are shown in the figure, both before and after two months of continuous phenytoin therapy. After the phenytoin therapy there was a marked reduction in plasma dexamethasone levels produced by oral intake of the steroid.

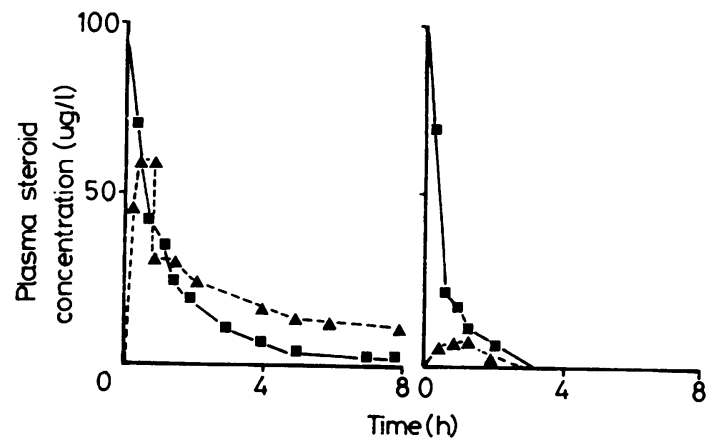

Fig Subject A. Time courses of plasma dexamethasone concentrations after oral (broken line) and intravenous administration (continuous line) of $4 \mathrm{mg}$ of the base before (left side) and two months after (right side) commencement of phenytoin therapy. Plasma dexamethasone levels are very much lower after oral steroid dosage following two months of phenytoin intake.
For testing the statistical significance of differences between the means, the data for subject $\mathrm{C}$ and the second set of data from subject $F$ were excluded from consideration. Subject $C$ had received a much higher dexamethasone dose than all other subjects and his terminal elimination half-life value was so much greater than that of other subjects that it was decided to regard him as an "outlier". In the studies in subjects not exposed to phenytoin, mean terminal phase plasma half-life (3.34 \pm SD $1 \cdot 15$ hours) was longer than in those who had received phenytoin $(1.81 \pm 1.78$ hours $)$, though the difference was not quite statistically significant $(t=2 \cdot 0881,0 \cdot 1>p>$ $0 \cdot 05$ ). Mean apparent volume of distribution was reasonably similar in the two groups $(1 \cdot 200 \pm$ SD $0.270 \mathrm{~L} . \mathrm{kg}^{-1}$ and $1.316 \pm \mathrm{SD} 0.875 \mathrm{~L} \cdot \mathrm{kg}^{-1}: \mathrm{t}=$ $0 \cdot 3329, \mathrm{p}>0 \cdot 7)$. Systemic clearance was statistically significantly lower $(\mathrm{t}=3.1816, \mathrm{p}<0.01)$ in those not exposed to phenytoin $(0 \cdot 272 \pm$ SD $0 \cdot 129$ L. $\left.\mathrm{kg}^{-1} \mathrm{hr}^{-1}\right)$ than in those receiving the

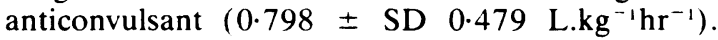
Mean oral bioavailability of dexamethasone was reasonably complete in the subjects not taking phenytoin $(0 \cdot 84 \pm$ SD $0 \cdot 23)$, but was substantially lower in those taking dexamethasone with phenytoin $(0.33 \pm$ SD 0.33$)$, the difference being statistically significant $(t=3.7222, p<0.005)$. Dexamethasone absorption rate constant after oral administration was reasonably high (arithmetic mean rate constant $2 \cdot 10 \pm$ SD 1.37 hour $^{-1}$ in those 
not receiving phenytoin, and $3 \cdot 18+3 \cdot 41$ hour $^{-1}$ in those taking this anticonvulsant).

It was notable that the oral bioavailability of dexamethasone in all but one subject taking the drug with phenytoin was 0.35 or less. The one exception (Subject M, with a bioavailability of 1.05 ) had taken phenytoin for only 24 hours before the oral bioavailability study began. All subjects with low oral bioavailabilities of the drug had taken phenytoin for at least 3 days. Excluding Subject M, there was no overlap in the oral bioavailability findings between the high values in those not taking phenytoin and the low values in those taking this anticonvulsant.

\section{Discussion}

The present investigation has shown that phenytoin intake is associated with a substantially lowered bioavailability of orally administered dexamethasone. Because the orally-administered steroid did not absorb more slowly in those receiving phenytoin than in those not receiving this anticonvulsant, the bioavailability difference is unlikely to depend on impaired absorption. Dexamethasone is eliminated from the body almost entirely by metabolism. ${ }^{8}$ For such a substance, with a mean clearance value after intravenous administration of

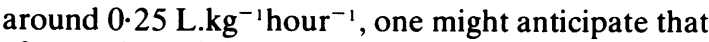
after oral administration there could be appreciable presystemic elimination on first passage through the liver. Consequently the oral bioavailability would tend to be somewhat incomplete. Should systemic clearance be increased further, as is known to happen after phenytoin intake, ${ }^{3}$ a finding which has been confirmed in the present study, one would expect that even higher proportions of an oral dose would be metabolised in the liver before reaching the general circulation. Thus the considerably reduced dexamethasone oral bioavailability following phenytoin intake could be explained. Exposure to the anticonvulsant would appear to induce the liver mono-oxygenase system, and thus increase the liver's enzymatic capacity for degrading dexamethasone. In the present study, the only subject taking phenytoin who did not have a considerably reduced dexamethasone oral bioavailability was the subject who, when first studied (by the oral route), had taken the anticonvulsant for only 24 hours. In another subject even after only 3 days of phenytoin intake the oral bioavailability of dexamethasone was substantially reduced. It thus seems that phenytoin may induce the liver's capacity to metabolise dexamethasone to a significant degree after only a few days exposure to the anticonvulsant. Since dexamethasone clearances tended to be higher in the subjects who had taken phenytoin for more than a few days it is possible that induction was not maximal when some of the subjects were studied.

The reduction in the oral bioavailability of dexamethasone associated with phenytoin intake is large enough to have implication for therapeutics. The matter may be particularly important in neurosurgery where dexamethasone may be given for life-threatening situations in persons who not infrequently also receive phentyoin to prevent epilepsy. If the data for subject $M$ in the present series are excluded, on the grounds that phenytoin exposure may not have been long enough to alter bioavailability in this subject, the mean fraction of an oral dexamethasone dose that reached the general circulation of the patients taking phenytoin was $0 \cdot 21$, whereas for those not taking phenytoin the corresponding figure was $0 \cdot 84$. Thus, if the experience of the present study is not atypical, the average patient taking dexamethasone by mouth, as well as phenytoin, may require four times as much steroid each day to achieve a given plasma dexamethasone level as would his fellow sufferer who did not take phenytoin. It is possible that failure to appreciate the size of the difference in steroid dose in the presence and the absence of phenytoin intake may have sometimes led to unnecessary therapeutic failure and even to death of patients.

\section{References}

' North, JB, Penhall RK, Hanich A, Frewin DB, Taylor WB. Phenytoin and postoperative epilespy. double-blind study. $J$ Neurosurg 1983;58:672-7.

2 Jubiz W, Meikle AW, Levinson RA, Mizutani S, West $\mathrm{CD}$, Tyler FH. Effect of diphenylhydantoin on the metabolism of dexamethasone. Mechanism of the abnormal dexamethasone suppression in humans. New Engl J Med 1970;283:11-14.

${ }^{3}$ Haque N, Thrasher K, Werk EE Jr, Knowles HC Jr, Sholiton LJ. Studies on dexamethasone metabolism in man: effect of diphenylhydantoin. J Clin Endocrinol 1972;34:44-50.

${ }^{4}$ Brophy TRO' R, McCafferty J, Tyrer JH, Eadie, MJ. Bioavailability of oral dexamethasone during high dose steroid therapy in neurological patients. Eur $J$ Clin Pharmacol 1983;24:103-0.

${ }^{5}$ Cham BE, Sadowski B, O'Hagan JM, DeWytt CN, Bochner F. Eadie MJ. High performance liquid chromatographic assay of dexamethasone in plasma and urine. Ther Drug Monit 1980;2:373-7.

- Gibaldi M, Perrier D. Pharmacokinetics. New York. Marcel Dekker. 1982. 2nd ed.

${ }^{7}$ Marquardt DM. An algorithm for least-squares estimation of nonlinear parameters. $J$ Society for Industrial and Applied Mathematics 1963;11:431-41.

* Tsuei SE, Moore RG, Ashley JI, McBride WG. Disposition of synthetic glucocorticoids. I. Pharmacokinetics of dexamethasone in healthy adults. J Pharmacokinet Biopharm 1979; 7:249-264. 